\title{
EFFECT OF NOZZLES, APPLICATION RATES, AND ADJUVANTS ON SPRAY DEPOSITION IN WHEAT CROPS
}

\author{
Willian A. Machado ${ }^{1}$, Sérgio M. Silva ${ }^{2}$, Stephan M. Carvalho ${ }^{3}$, João P. A. R. da Cunha ${ }^{*}$ \\ ${ }^{4 *}$ Corresponding author. Universidade Federal de Uberlândia/ Uberlândia - MG, Brasil. E-mail: jpcunha@iciag.ufu.br \\ ORCID ID: https://orcid.org/0000-0001-8872-3366
}

\begin{abstract}
KEYWORDS
Triticum aestivum; application technology; spray mixture volume; droplet spectrum; insecticide drift.
\end{abstract}

\begin{abstract}
The use of insecticides is common in pest management in wheat crops but may lead to higher production costs and environmental contamination. Therefore, a more comprehensive and uniform distribution of plant protection products in the desired target is recommended. The objective of this study is to evaluate the effect of different spray nozzles, application rates, and adjuvants on droplet spectrum and spray deposition in wheat crops. The physicochemical characteristics of the spray mixture, droplet spectrum, and spray deposition in wheat plants were evaluated. The lower application rate $(75 \mathrm{~L}$ $\mathrm{ha}^{-1}$ ) combined with the use of the twin flat fan tip AS7030 and the adjuvant sodium lauryl ether sulfate (SLES) yielded droplets with a larger diameter. However, insecticide spraying using hollow cone tip MGA 015 without adjuvants provided the highest percentage of droplets susceptible to drift. SLES significantly decreased the percentage of drift by increasing droplet size, and the adjuvant silicone, d-limonene, and polyester copolymer increased spray deposition. The evaluated adjuvants increased the electrical conductivity and reduced the surface tension of the spray mixtures. These results indicate that it is possible to reduce the application rate from 150 to $75 \mathrm{~L} \mathrm{ha}^{-1}$ without affecting spray deposition on wheat leaves.
\end{abstract}

\section{INTRODUCTION}

The cultivation of wheat (Triticum aestivum L.; Gramineae, Triticaceae) is of great relevance to agricultural production in Brazil. Despite estimates of record production, Brazil has not yet reached self-sufficiency in producing wheat because crop yield is affected by abiotic factors, including climate, soil, and nutrition, and biotic factors, especially pests and diseases.

The green aphid (Schizaphis graminum Rondani, 1852) (Hemiptera: Aphididae) is the main pest insect responsible for causing significant economic losses to wheat crops, primarily by injecting toxins into plant tissues during feeding, causing yellowing, drying, and plant death. Therefore, the control of this pest is recommended when $10 \%$ of the plants are attacked.

Chemical control is common to avoid high infestations of aphids but increases production costs, environmental contamination, and public health problems. Therefore, insecticide application is a relevant factor when choosing the application technology to be employed and should guarantee the efficient deposition of the chemical product in the desired target to avoid insecticide drift (Van Zil et al., 2013).

At present, insecticide spraying for pest control is optimized to reduce the rate of application. However, this optimization affects the performance of plant protection products, and higher application rates may increase product deposition in the target plants only to a certain extent, and the use of high doses may lead to runoff, increasing environmental contamination (Ferguson et al., 2016). By contrast, lower application rates may increase product coverage and efficiency, increase the operational capacity of sprayers, and decrease production costs (Tavares et al., 2017).

Adjuvants can improve the performance of plant protection products and increase the effectiveness of pest control. These substances may help reduce the rate of application by modifying the physicochemical characteristics of the spray mixture, including surface tension, viscosity, $\mathrm{pH}$, and electrical conductivity. For this

\footnotetext{
${ }^{1}$ Universidade Federal de Uberlândia/ Uberlândia - MG, Brasil.

${ }^{2}$ Universidade Federal dos Vales do Jequitinhonha e Mucuri/ Unaí - MG, Brasil.

${ }^{3}$ Universidade Federal de Lavras/ Lavras - MG, Brasil.

Received in: 5-24-2018

Accepted in: 10-25-2018
} 
reason, the process of droplet formation can be changed, allowing greater spreading and adhesion of droplets to the leaf surface, improving pest control (Hilz \& Vermeer, 2013).

It is believed that all these factors strongly affect pest management in several crops, including wheat crops, for which there is little information about the impact of lower rates of application and adjustment of droplet size to improve the effectiveness of chemical control and the sustainability of insecticide spraying. The objective of this study was to evaluate the effect of different spray nozzles, application rates, and adjuvants on droplet spectrum and spray deposition in wheat crops.

\section{MATERIAL AND METHODS}

\section{Experimental site}

The experiments were performed in duplicate in two areas located at Fazenda Maringá in the municipality of
Araguari $\left(18^{\circ} 34^{\prime} 00.23^{\prime \prime S}\right.$ and $\left.48^{\circ} 13^{\prime} 03.9^{\prime \prime} \mathrm{W}\right)$, state of Minas Gerais, Brazil. The areas were spaced $500 \mathrm{~m}$ apart, presented a central pivot irrigation system and, during the experiments, were used for producing wheat seeds of cultivar BRS 404.

The wheat crop was sowed under a no-tillage system in areas 1 and 2 on April 4 and April 8 of 2016, respectively. The inter-row spacing was $17 \mathrm{~cm}$, and the plant density was $350 \mathrm{~m}^{-2}$.

\section{Experimental design}

The experiments were conducted in continuous strips, with seven treatments and three replicates (Table 1). Each plot had a length of $740 \mathrm{~m}$ and width of $27 \mathrm{~m}$. The evaluated useful area corresponded to $1,800 \mathrm{~m}^{2}$, discarding $10 \mathrm{~m}$ at the beginning and end of the cultivation area and 1 $\mathrm{m}$ on each side.

TABLE 1. Treatments used to evaluate spray deposition in wheat crop using different spray tips, application rates, and adjuvants.

\begin{tabular}{cccc}
\hline Treatment & Spray tip & $\begin{array}{c}\text { Application rate } \\
\left(\text { L ha }^{-1}\right)\end{array}$ & Adjuvant \\
\hline 1 & AS7030 & 75 & - \\
2 & MGA 015 & 75 & - \\
3 & MGA 015 & 75 & SLES $^{1}$ \\
4 & AS7030 & 75 & SLES \\
5 & AS7030 & 75 & SLPC $^{2}$ \\
6 & MGA 03 & 150 & - \\
7 & MGA 03 & 150 & SLES \\
\hline
\end{tabular}

${ }^{1}$ Sodium lauryl ether sulfate; ${ }^{2}$ Silicone, d-limonene, and polyester copolymer;

All spray tips used were model MagnoJet (Ibaiti, Paraná, Brazil): 1. MGA 015, hollow cone with $90^{\circ}$ angulation and flow rate of $0.56 \mathrm{~L} \mathrm{~min}^{-1} ; 2$. MGA 03 , hollow cone with $90^{\circ}$ angulation and flow rate of $1.13 \mathrm{~L} \mathrm{~min}^{-1}$; and 3. AS7030, asymmetrical twin flat fan with $110^{\circ}$ angulation and flow rate of $0.75 \mathrm{~L} \mathrm{~min}^{-1}$.

The adjuvants used were 1 . sodium lauryl ether sulfate (SLES) - Mirus $400 \mathrm{Si}^{\circledR}$, at a concentration of $0.6 \mathrm{~mL}$ $\mathrm{L}^{-1}$, with anti-evaporating, acidifying, anti-drift, and antifoam properties; 2. silicone, d-limonene, and polyester copolymer (SLPC) - Orlist $900 \mathrm{Li}^{\circledR}$, at a concentration of $1.33 \mathrm{~mL} \mathrm{~L}^{-1}$, with spreading, humectant, compatibilizing, and penetrating properties.

The spray solutions were prepared as tank mixtures, adding the above adjuvants at the concentration recommended by the manufacturer, together with insecticide imidacloprid at $200 \mathrm{~g}$ active ingredient $\mathrm{ha}^{-1}$ (Galeão, Helm do Brasil).

\section{Applications of treatments}

Insecticides were sprayed when green aphid infestations in wheat crops reached $10 \%$ of the plants. A Case $^{\circledR}$ Patriot 250 self-propelled sprayer was used, with a boom length of $27 \mathrm{~m}$ and nozzle spacing of $0.5 \mathrm{~m}$. A working speed of $16 \mathrm{~km} \mathrm{~h}^{-1}$ was used in all treatments.

The environmental conditions during spraying were monitored using a digital thermo-hygrometer-anemometer model Skill-Tec ${ }^{\circledR}$ SKTHAL-01. During spraying in area 1, the minimum and maximum temperature was 25.4 and 29.5 ${ }^{\circ} \mathrm{C}$, respectively, relative humidity was $48-51 \%$, and wind speed was $5.8-7.9 \mathrm{~km} \mathrm{~h}^{-1}$. In area 2 , the minimum and maximum temperature was 30.7 and $32.4{ }^{\circ} \mathrm{C}$, respectively, relative air humidity was $43-45 \%$, and wind speed was 0.8 $5.2 \mathrm{~km} \mathrm{~h}^{-1}$. The parameters evaluated in this phase were the physicochemical characteristics of the spray mixture, droplet spectrum, and spray deposition.

\section{Physicochemical characteristics}

The physicochemical characteristics evaluated in the samples were $\mathrm{pH}$, electrical conductivity, density, dynamic viscosity, and surface tension. The samples were collected immediately after preparing the sprays for treatment applications. The samples were placed in a $0.5-\mathrm{L}$ amber jar, identified, stored in a thermal box, and sent to the Agricultural Mechanization Laboratory of the Federal University of Uberlândia.

The $\mathrm{pH}$ and electrical conductivity were evaluated using a Hanna HI98139 digital pH meter and conductivity meter, respectively. The equipment was previously calibrated using standard solutions at $\mathrm{pH} 4.00$ and 6.86. The density was estimated by calculating the mass of $0.1 \mathrm{~L}$ of the solution deposited in a volumetric flask at a scale of 0.1 mg.

Dynamic viscosity was determined using a Quimis Q860M21 microprocessor rotary viscometer, which allowed electronically measuring the torsional force previously converted to viscosity. The principle of cylinder rotation was used, in which the cylinder was submerged in the sample to be analyzed, and the torsional force necessary to overcome the resistance of rotation was measured. Rotor zero and a frequency of $60 \mathrm{rpm}$ were used for these determinations. 
The surface tension was determined using a Kruss K6 bench tensiometer with a platinum ring and the Du Nouy method (Dopierala \& Prochaska, 2008). This equipment was calibrated with distilled water. Water was used as the control in all assays used to determine the physicochemical characteristics of the spray mixtures.

\section{Droplet spectrum}

For evaluating the droplet spectrum, five Syngenta Crop Protection watersensitive papers (76 x $26 \mathrm{~mm}$ ) were used in each treatment. Each paper was placed next to the main stem of the wheat plant, between the flag leaf and the spike, before spraying.

After spraying, the papers were collected and stored in envelopes to avoid contact with atmospheric humidity. Subsequently, the papers were scanned at a spatial resolution of 1564 dpi using DropScope $\AA$ software version 2016.1124.1. The following parameters were assessed: volume median diameter (VMD), relative amplitude (RA), and volume percentage of droplets with a diameter of less than $100 \mu \mathrm{m}(\mathrm{D}<100 \mu \mathrm{m})$.

\section{Spray deposition}

For evaluating spray deposition in wheat plants, a blue dye (Duas Rodas, Jaraguá do Sul, Santa Catarina, Brazil), internationally cataloged by the "Food, Drug, and Cosmetic" as FD \& C Blue $n^{\circ} 1$, was applied to the tank mixture. A dose of $300 \mathrm{~g} \mathrm{ha}^{-1}$ was used in all treatments.

Immediately after each treatment, five samples containing flag leaves and spikes were collected in each plot. These plant parts were chosen as targets for measuring spray deposition because of the preference of aphids for these sites. Subsequently, the individualized and labeled samples were conditioned in plastic bags and kept in a thermal box for later manipulation in the laboratory.

The dye was removed by adding $50 \mathrm{~mL}$ of distilled water to each plastic bag containing a sample, and the bag was shaken for $30 \mathrm{~s}$ to homogenize the mixture. Then, the liquid was drained and transferred to plastic cups, which were maintained in a refrigerator for 24 hours in the dark.

The supernatant was analyzed by absorbance reading in a spectrophotometer model SP-22 (Biospectro, Curitiba, Paraná, Brazil) at a wavelength of $630 \mathrm{~nm}$ using a quartz cuvette with an optical path of $10 \mathrm{~mm}$ and volume of 3.5 $\mathrm{mL}$. A calibration curve with different concentrations of the dye was created to estimate the amount of dye in each sample according to the equation $\mathrm{y}=0.0044 \mathrm{x}-0.0011, \mathrm{R}^{2}$ $=99.9 \%$, where $\mathrm{y}$ is the amount of dye $\left(\mathrm{mg} \mathrm{L}^{-1}\right)$ and $\mathrm{x}$ is absorbance. In flag leaves, the total stained area was divided by the leaf area to obtain the amount (in $\mu \mathrm{g}$ ) of dye per leaf area. The leaf area was analyzed using a Li-3100 Licor leaf area meter (Lincoln Inc., Nebraska, USA). The total amount of dye in the spikes was divided by the dry mass of each sample to obtain the amount of dye (in $\mu \mathrm{g}$ ) per gram of dry mass of spike. The spike mass was obtained after drying the samples in a forced-air circulation oven model LUCA82/480 (Lucadema, São José do Rio Preto, São Paulo, Brazil) at $65^{\circ} \mathrm{C}$ for 72 hours, and the samples were weighed on a precision scale model ALC-210.4ACCULAB (Sartorius Group, Göttingen, Germany).

\section{Statistical analysis}

The results were first subjected to the residual-based Kolmogorov-Smirnov test for normality and Levene's test of homogeneity of variance, both at a level of significance of $1 \%$. After that, the means were analyzed using Student's $t$-test for independent samples at a level of significance of $5 \%$.

\section{RESULTS AND DISCUSSION}

\section{Physicochemical characteristics}

The average values of $\mathrm{pH}$, electrical conductivity, dynamic viscosity, density, and surface tension of the spray mixture as a function of the application rates and adjuvants in wheat crops are presented in Tables 2 and 3.

TABLE 2. $\mathrm{pH}$ and electrical conductivity of spray mixtures as a function of application rates and adjuvants in wheat crops.

\begin{tabular}{|c|c|c|c|c|}
\hline $\begin{array}{c}\text { Spray/ } \\
\text { Adjuvants }\end{array}$ & $\begin{array}{c}\text { Concentration } \\
\left(\mathbf{m L ~ L} \mathbf{L}^{-1}\right)\end{array}$ & $\begin{array}{l}\text { Application rate } \\
\qquad\left(\mathrm{L} \mathrm{ha}^{-1}\right)\end{array}$ & pH & $\begin{array}{c}\text { Electrical conductivity } \\
\left(\mu \mathrm{S} \mathrm{cm}^{-1}\right) \\
\end{array}$ \\
\hline Without adjuvant $^{1}$ & - & 75 & $6.42 \pm 0.020$ & $583.4 \pm 6.5543 b$ \\
\hline SLES $^{1}$ & 0.6 & 75 & $4.48 \pm 0.020$ & $875.6 \pm 6.1773 a$ \\
\hline SLPC $^{3}$ & 1.33 & 75 & $6.78 \pm 0.020$ & $570.6 \pm 2.2045 b$ \\
\hline Without adjuvant & - & 150 & $6.46 \pm 0.024$ & $402.8 \pm 0.2000 \mathrm{c}$ \\
\hline SLES & 0.6 & 150 & $5.76 \pm 0.024$ & $567.2 \pm 2.2226 b$ \\
\hline Water & - & - & $6.80 \pm 0.054$ & $11.88 \pm 0.3426 \mathrm{~d}$ \\
\hline
\end{tabular}

The means followed by different letters in each column were significantly different from each other using Student's $t$-test at a level of significance of $5 \%$.

${ }^{1}$ Insecticide only; ${ }^{2}$ Sodium lauryl ether sulfate; ${ }^{3}$ Silicone, d-limonene, and polyester copolymer. 
TABLE 3. Average values of dynamic viscosity, density, and surface tension of spray mixtures as a function of application rates and adjuvants in wheat crops.

\begin{tabular}{|c|c|c|c|c|c|}
\hline $\begin{array}{c}\text { Spray/ } \\
\text { Adjuvants }\end{array}$ & $\begin{array}{l}\text { Concentration } \\
\quad\left(\mathbf{m L ~ L ~} \mathbf{L}^{-1}\right)\end{array}$ & $\begin{array}{c}\text { Application } \\
\text { rate } \\
\left(\mathrm{L} \mathrm{ha}^{-1}\right) \\
\end{array}$ & $\begin{array}{l}\text { Viscosity } \\
\text { (mPa s) }\end{array}$ & $\begin{array}{c}\text { Density } \\
\left({\left.\mathrm{g} 100 \mathrm{~cm}^{-3}\right)}^{-}\right.\end{array}$ & $\begin{array}{l}\text { Surface tension } \\
\quad\left(\mathrm{mN} \mathrm{m}^{-1}\right)\end{array}$ \\
\hline Without adjuvant $^{1}$ & - & 75 & $1.484 \pm 0.032$ & $99.774 \pm 0.0050$ & $26.8 \pm 0.122 b$ \\
\hline SLES $^{1}$ & 0.6 & 75 & $1.500 \pm 0.010$ & $99.776 \pm 0.0067$ & $27.6 \pm 0.244 \mathrm{~b}$ \\
\hline SLPC $^{3}$ & 1.33 & 75 & $2.248 \pm 0.028$ & $99.816 \pm 0.0050$ & $23.6 \pm 0.244 \mathrm{~b}$ \\
\hline Without adjuvant & - & 150 & $1.608 \pm 0.013$ & $99.668 \pm 0.0037$ & $26.6 \pm 0.244 \mathrm{~b}$ \\
\hline SLES & 0.6 & 150 & $1.586 \pm 0.032$ & $99.642 \pm 0.0037$ & $27.0 \pm 0.316 \mathrm{~b}$ \\
\hline Water & - & - & $1.040 \pm 0.029$ & $99.704 \pm 0.0256$ & $75.2 \pm 0.122 \mathrm{a}$ \\
\hline
\end{tabular}

The means followed by different letters in each column were significantly different from each other using Student's $t$-test at a level of significance of $5 \%$.

${ }^{1}$ Insecticide only; ${ }^{2}$ Sodium lauryl ether sulfate; ${ }^{3}$ Silicone, d-limonene, and polyester copolymer.

There were significant differences in electrical conductivity and surface tension between the treatments (Tables 2 and 3). However, there were no significant differences in $\mathrm{pH}$, viscosity, and density between the treatments.

The addition of adjuvants did not change the $\mathrm{pH}$ of the spray mixture. It is known that mixture $\mathrm{pH}$ is a crucial factor because it can affect product efficiency, inducing the inactivation or degradation of active ingredients. The rate of hydrolysis of some plant protection products is decreased as the mixture $\mathrm{pH}$ is decreased, which keeps the leaves wetter for a longer time because the leaf surface, which usually has a neutral $\mathrm{pH}$, interacts with the product $\mathrm{pH}$ (Cunha et al., 2010a), potentially increasing the efficiency of pesticides. However, this effect is less pronounced in insecticides.

All evaluated mixtures presented higher values of electrical conductivity when compared to water, especially the treatment containing the adjuvant SLES, which presented the highest conductivity. Adjuvants may have different effects on electrical conductivity. Cunha et al. (2010a) found that the adjuvants polyether polymethyl copolymer, glycol fatty acid esters, and mineral oil reduced the conductivity of spray mixtures whereas the methyl ester of soybean oil increased conductivity. Zandonadi et al. (2017) reported that this variable was related to the concentration and charge of ions in the solution, i.e., the chemical composition of each product.

In the present study, dynamic viscosity and density were not affected by the adjuvants. Although the increase in density may decrease drift, this process is not easily achieved in practice because the concentration of the adjuvants in spray mixtures is usually low.

Some adjuvants can change the viscosity of spray mixtures. Cunha et al. (2010b) obtained significant results on the viscosity of mixtures containing the adjuvant phosphatidylcholine and propionic acid. In application technology, increasing the viscosity of the spray mixture by adding adjuvants is an effective strategy for reducing drift. Fluids with higher viscosity and surface tension usually require more energy for spraying, producing larger droplets and consequently reducing the risk of drift.

All spray mixtures presented a significantly lower surface tension compared to water. This result may be due to the presence of surfactants in the adjuvants and insecticide formulation. Decreasing surface tension may improve the retention or adhesion of products to the foliar surface to a certain extent, increasing spray coverage (Yu et al., 2009).

Baio et al. (2015) reported that the decrease in the surface tension might allow higher leaf wetness, facilitating the spread of spray droplets to the target sites, improving the retention/absorption of the active ingredient by the plant and consequently the effectiveness of pest control.

\section{Droplet spectrum}

The average values of VMD, D $<100 \mu \mathrm{m}$, and RA as a function of spray tips, application rates, and adjuvants in wheat crops are shown in Table 4.

TABLE 4. Mean values of volume median diameter (VMD), volume percentage of droplets with a diameter smaller than 100 $\mu \mathrm{m}(\mathrm{D}<100 \mu \mathrm{m})$, and relative amplitude $(\mathrm{RA})$ as a function of spray tips, application rates (AR), and adjuvants in wheat crops.

\begin{tabular}{|c|c|c|c|c|c|c|c|c|}
\hline \multirow{2}{*}{ Tips } & \multirow{2}{*}{$\begin{array}{c}\mathrm{AR} \\
\left(\mathrm{L} \mathrm{ha}^{-1}\right)\end{array}$} & \multirow{2}{*}{ Adjuvant } & \multicolumn{2}{|c|}{ VMD $(\mu \mathrm{m}) *$} & \multicolumn{2}{|c|}{$\mathrm{D}<100 \mu \mathrm{m}(\%)$} & \multicolumn{2}{|c|}{ RA } \\
\hline & & & Area 1 & Area 2 & Area 1 & Area 2 & Area 1 & Area 2 \\
\hline AS7030 & 75 & Without adjuvant ${ }^{1}$ & $326.86 b$ & $370.03 a$ & $1.69 \mathrm{c}$ & $1.82 \mathrm{~b}$ & $0.978 b$ & $0.804 \mathrm{a}$ \\
\hline MGA 015 & 75 & Without adjuvant & $202.71 \mathrm{c}$ & $215.71 \mathrm{c}$ & $6.70 \mathrm{a}$ & $6.37 \mathrm{a}$ & $0.812 \mathrm{a}$ & $0.872 \mathrm{a}$ \\
\hline MGA 015 & 75 & SLES $^{1}$ & $220.76 \mathrm{c}$ & $240.30 \mathrm{c}$ & $2.57 \mathrm{~b}$ & $2.65 b$ & $0.822 \mathrm{a}$ & $0.916 \mathrm{a}$ \\
\hline AS7030 & 75 & SLES & $388.53 \mathrm{a}$ & $382.36 \mathrm{a}$ & $1.02 \mathrm{~d}$ & $1.41 \mathrm{~d}$ & $0.898 \mathrm{~b}$ & $1.168 \mathrm{~b}$ \\
\hline AS7030 & 75 & SLPC $^{3}$ & $317.61 b$ & $317.61 b$ & $1.46 \mathrm{c}$ & $1.59 \mathrm{c}$ & $0.982 b$ & $0.980 \mathrm{a}$ \\
\hline MGA 03 & 150 & Without adjuvant & $292.94 b$ & $280.60 \mathrm{~b}$ & $2.48 \mathrm{~b}$ & $2.76 b$ & $0.972 b$ & $0.990 \mathrm{a}$ \\
\hline MGA 03 & 150 & SLES & $302.19 b$ & $287.09 \mathrm{~b}$ & $1.78 \mathrm{c}$ & $1.66 \mathrm{c}$ & $0.968 \mathrm{~b}$ & $0.876 a$ \\
\hline
\end{tabular}

The means followed by different letters in each column were not significantly different from each other using Student's $t$-test at a level of significance of $5 \%$. *The size of spray droplets was classified by the software program as very fine $(<150 \mu \mathrm{m})$, fine $(150-250 \mu \mathrm{m})$, medium $(250-350 \mu \mathrm{m})$, large $(350-450 \mu \mathrm{m})$, very large $(450-550 \mu \mathrm{m})$, and extremely large $(>550 \mu \mathrm{m}) .{ }^{1}$ Insecticide only; ${ }^{2}$ Lauryl ether sodium sulfate; ${ }^{3}$ Silicone, d-limonene, and polyester copolymer. 
The combinations of spray tips, ARs, and adjuvants yielded different droplet spectra (Table 4). The VMD values were relatively higher in area 2 using the AS7030 twin flat fan tip at an application rate of $75 \mathrm{~L} \mathrm{ha}^{-1}$ and in area $1 \mathrm{using}$ the same combination + SLES, leading to an increase in droplet size (Table 4).

With regard to the effect of SLES on the increase in droplet size, Mota et al. (2010) evaluated the effect of SLES in admixture with the herbicide paraquat and found significant differences between the spray mixtures containing adjuvant alone, adjuvants + herbicide, and herbicide alone. There was an increase in VMD and a decrease in $\mathrm{D}<100 \mu \mathrm{m}$ in spray mixtures containing SLES.

SLES is classified as an adhesive spreader, belonging to the chemical group of polydimethylsiloxanes. The results indicated that SLES had the potential to decrease $\mathrm{D}<100 \mu \mathrm{m}$ using both tips, confirming the good performance of the adjuvant in reducing this parameter. The lower is this value, the lower is the risk of drift, resulting in safer insecticide applications with less environmental impact.

In contrast, the smaller droplet diameters were obtained using the hollow cone tip MGA 015 associated to a lower application rate without adjuvant. This same combination produced the highest percentage of drift-prone droplets with a diameter of less than $100 \mu \mathrm{m}$ in the two experimental areas, even in the presence of SLES, despite a slight increase in VMD. Furthermore, the use of SLPC decreased droplet diameter considering that the comparison of the applications using the AS7030 tip at $75 \mathrm{~L} \mathrm{ha}^{-1}$ indicated a significant reduction of VMD in the presence of this adjuvant. Román et al. (2009) evaluated adjuvants with anti-drift potential using tips that produced lower VMD and obtained similar results. Smaller droplet size may result in better leaf coverage and improve treatment performance.

In the current application technology, a significant challenge is reducing the risk of contamination caused by the loss of plant protection products to the environment. It is known that the use of fine droplets in the presence of strong winds changes the trajectory of the droplets, causing greater drift and possible adverse effects on non-target organisms. In the present study, the MGA hollow cone tip presented a higher drift potential, although it caused less droplet spillage.

Therefore, it is necessary to consider the main rationale of spraying technology, which is the application of biologically active products to the target area using the correct amount, with the minimum contamination of other areas.

The RA values were higher using the AS7030 tips, with relatively higher variability in the droplet spectrum. However, the treatments using the hollow cone tip MGA 015 in the presence or absence of adjuvants at a rate of $75 \mathrm{~L}$ $\mathrm{ha}^{-1}$ had the lowest RA values, indicating a relatively lower variability in droplet spectrum. The higher variability in droplet spectrum is related to the higher RA values, i.e., the higher is the RA value, the higher is the variability in the droplet size produced, and a homogeneous droplet spectrum should have an RA value close to zero.

\section{Spray deposition}

The deposition of the bright blue dye on spikes and flag leaves during spray application as a function of spray tips, ARs, and use of adjuvants in wheat crops are shown in Table 5 .

TABLE 5. Average deposition of the bright blue dye on spikes and flag leaves during insecticide application using different spray tips, application rates (AR), and adjuvants in wheat crops.

\begin{tabular}{|c|c|c|c|c|c|c|}
\hline \multirow[t]{2}{*}{ Spray tips } & \multirow{2}{*}{$\begin{array}{c}\mathbf{A R} \\
\left(\mathbf{L ~ h a} \mathbf{h a}^{-1}\right)\end{array}$} & \multirow[t]{2}{*}{ Adjuvants } & \multicolumn{2}{|c|}{$\begin{array}{c}\text { Dye deposition on spikes } \\
\left(\mu \mathrm{g} \mathrm{g}^{-1}\right)\end{array}$} & \multicolumn{2}{|c|}{$\begin{array}{c}\text { Dye deposition on leaves } \\
\left(\mu \mathrm{g} \mathrm{cm}^{-2}\right)\end{array}$} \\
\hline & & & Area 1 & Area 2 & Area 1 & Area 2 \\
\hline AS7030 & 75 & Without adjuvant $^{1}$ & $155.34 \mathrm{~b}$ & $167.94 \mathrm{c}$ & $5.50 \mathrm{c}$ & $11.15 \mathrm{c}$ \\
\hline MGA 015 & 75 & Without adjuvant & $153.52 b$ & $169.69 \mathrm{c}$ & $8.89 \mathrm{c}$ & $11.23 \mathrm{c}$ \\
\hline MGA 015 & 75 & SLES $^{1}$ & $185.33 \mathrm{a}$ & $215.53 a$ & $11.11 \mathrm{a}$ & $18.20 \mathrm{a}$ \\
\hline AS7030 & 75 & SLES & $160.09 b$ & $190.66 b$ & $9.11 \mathrm{~b}$ & $13.83 b$ \\
\hline AS7030 & 75 & $\mathrm{SLPC}^{3}$ & $184.22 \mathrm{a}$ & $208.38 \mathrm{a}$ & $11.68 \mathrm{a}$ & $17.02 \mathrm{a}$ \\
\hline MGA 03 & 150 & Without adjuvant & $167.84 b$ & $201.26 \mathrm{a}$ & $10.31 \mathrm{a}$ & $15.76 \mathrm{a}$ \\
\hline MGA 03 & 150 & SLES & $176.22 \mathrm{a}$ & $207.16 \mathrm{a}$ & $10.91 \mathrm{a}$ & $17.20 \mathrm{a}$ \\
\hline
\end{tabular}

${ }^{1}$ The means followed by different letters in each column were significantly different from each other using Student's $t$-test at a level of significance of $5 \%$.

${ }^{1}$ Only insecticide; ${ }^{2}$ Lauryl ether sodium sulfate; ${ }^{3}$ Silicone, d-limonene, and polyester copolymer.

Dye deposition on flag leaves and spikes was significantly different between the treatments. In the two experimental areas, deposition on flag leaves and spikes at a rate of $75 \mathrm{~L} \mathrm{ha}^{-1}$ was higher using the combinations SLES + MGA 015 tip and CPSDL + AS7030 tip. At the highest rate of application, dye deposition was comparatively higher using the MGA 03 tip + SLES. This result demonstrates that it is possible to reduce the rate of application without affecting spray deposition in the evaluated targets (Table 5).

This result corroborates that of previous studies (Tavares et al., 2017) on the feasibility of reducing the rate of application to guarantee higher spray deposition in the upper canopy of the crop, increasing the performance of insecticides. In addition, one of the major advantages of reducing the rate of application is optimizing the process, with cost reduction and less environmental contamination.

The higher spray deposition on the plant canopy is justified by the greater proximity of the canopy to the site of droplet formation/emission. Spray deposition in area 2 was relatively smaller using the tips AS7030 and MGA015 at the lower rates of application and in the absence of adjuvants. These results highlight the importance of using adjuvants to ensure better coverage of target sites when using smaller spray volumes. 
These results are in line with those of Bueno et al. (2013), who used different application rates in potato crops and found that losses to the environment were higher with higher application rates in the absence of adjuvants. Therefore, the analysis of the physicochemical properties of the evaluated adjuvants indicated their ability to reduce surface tension and their anti-drift and adhesive spreading properties, with a potential improvement in spray cover and leaf wetness.

This fact can be observed by analyzing SLES + the hollow cone tip MGA 015, which caused the highest spray deposition in the crop possibly by increasing the diameter of the droplets produced by the tip. In contrast, the analysis of the droplet spectrum indicated that the greatest disadvantage of using this technology was the higher risk of drift caused by MGA 015 in the absence of SLES, increasing environmental contamination.

Therefore, it is necessary to use flat fan tips such as AS7030, which produces droplets that are larger and less susceptible to drift, with a spray deposition similar to that achieved by the MGA 015 tip at the lower application rate in the presence of SLPC. This adjuvant in the AS7030 tip reduced droplet diameter and spray runoff.

\section{CONCLUSIONS}

The evaluated adjuvants increased the electrical conductivity and reduced the surface tension of the spray mixtures.

The SLES adjuvant presented good performance in reducing insecticide drift by increasing the droplet size. In contrast, the adjuvant SLPC increased drift by reducing droplet size.

It is possible to reduce the rate of application to optimize insecticide spraying in wheat crops without compromising spray deposition in the desired target.

\section{REFERENCES}

Baio FHR, Gabriel RRF, Camolese HDAS (2015)

Alteração das propriedades físico-químicas na aplicação contendo adjuvantes. Brazilian Journal of Biosystems Engineering 9(2):151-161.

Bueno MR, Cunha JPAR, Alves GS (2013) Deposição de calda na aplicação aérea e terrestre de fitossanitário na cultura da batata. Engenharia Agrícola 33(6):1210-1222.

Cunha JPAR, Alves GS, Reis EF (2010a) Temperature effect on the physical-chemical characteristics of aqueous solutions with spray adjuvants. Planta daninha 28(3):665-672.
Cunha JPAR, Bueno MR, Ferreira MC (2010b) Espectro de gotas de pontas de pulverização com adjuvantes de uso agrícola. Planta Daninha 28:1153-1158.

Dopierala K, Prochaska K (2008) The effect of molecular structure on the surface properties of selected quaternary ammonium salts. Journal of Colloid Interface Science 321(1):220-226. DOI:

https://doi.org/10.1016/j.jcis.2008.01.049

Ferguson JC, Chechetto RG, Hewitt AJ, Chauhan BS, Adkins ST, Kruger GR, O'Donnell CC (2016) Assessing the deposition and canopy penetration of nozzles with different spray qualities in an oat (Avena sativa L.) canopy. Crop Protection 81(1):14-19.

Hilz ZE, Vermeer AWP (2013) Spray drift review: the extent to which a formulation can contribute to spray drift reduction. Crop Protection 44(1):75-83.

Mota AAB, Antuniassi UR, Oliveira RB, Chechetto RG, Silva ACA (2010) Espectro de gotas da pulverização de herbicida com e sem a adição de adjuvante na calda. In: Congresso Brasileiro da Ciência das Plantas Daninha. Ribeirão Preto, Sociedade Brasileira da Ciência das Plantas Daninhas, Anais...

Román RAA, Cortez JW, Ferreira MC, Oliveira JRGD (2009) Cobertura da cultura da soja pela calda fungicida em função de pontas de pulverização e volumes de aplicação. Scientia Agraria 10(3):223-232. DOI: https://doi.org/10.5380/rsa.v10i3.14529

Tavares RM, Silva JER, Alves GS, Alves TC, Silva SM, Cunha JPAR (2017) Tecnologia de aplicação de inseticidas no controle da lagarta-do-cartucho na cultura do milho. Revista Brasileira de Milho e Sorgo 16(1):30-42.

Van Zil JG, Fourie PH, Schutte GC (2013) Spray deposition assessment and benchmarks for control of Alternaria brown spot on mandarin leaves with copper oxychloride. Crop Protection 46(4):80-87.

Yu Y, Zhu H, Frantz JM, Reding ME, Chan KC, Ozkan HE (2009) Evaporation and coverage area of pesticide droplets on hairy and waxy leaves. Biosystems Engineering 104(3):324-334.

Zandonadi CHS, Cunha JPAR, Alves TC, Silva SM (2017) Tank mixture of pesticides for Spodoptera frugiperda control in maize with triflumuron. Bioscience Journal 33(1):31-40. 